\title{
FNAC Diagnosis of Soft Tissue Tumour (Proliferative Fascitis and Proliferative Myositis ): A Case Report
}

\author{
Sushma K. L.*, Nandini N. Manoli, Vasudha Nassa, Jayshree K., Manjunath G. V. \\ Department of Pathology, JSS medical college, A Constituent of JSS University, Mysore, India \\ Email address: \\ sushma.kenkere@gmail.com (Sushma K. L.)

\section{To cite this article:} \\ Sushma K. L., Nandini N. Manoli, Vasudha Nassa, Jayshree K., Manjunath G. V.. FNAC Diagnosis of Soft Tissue Tumour (Proliferative \\ Fascitis and Proliferative Myositis ): A Case Report. Science Journal of Clinical Medicine. Special Issue: Latest Different Concepts of \\ Gynaecology. Vol. 4, No. 4-1, 2015, pp. 23-25. doi: 10.11648/j.sjcm.s.2015040401.16
}

\begin{abstract}
Nodular fascitis is a benign fibroblastic tumour characterized by rapid growth and most of the time requires its differentiation from other tumorous lesions. Here is a case of 45 year old male who presented with a soft tissue swelling in the popliteal region. On FNAC, a differential diagnosis of proliferative myositis and proliferative fasciitis was given. Histopathological examination gave a diagnosis of nodular fascitis. Hence cytology helps to give a definite diagnosis and aid in the surgical management of soft tissue tumors.
\end{abstract}

Keywords: Soft Tissue Tumor, Proliferative Fascitis, Proliferative Myositis

\section{Introduction}

Proliferative fascitis and myositis are benign lesions that are often misdiagnosed as sarcoma ${ }^{(1)}$, leading to unnecessary surgery and chemotherapy. Nodular fascitis is usually a self limiting condition arising most commonly from the subcutaneous and fascial tissues ${ }^{(2)}$.

Konwaler et al. first reported nodular fascitis in 1955, as a subcutaneous pseudosarcomatous fibromatosis. Later Price et al., used the term nodular fascitis in 1961. Its diagnosis is often a challenge because it may be confused with a malignant tumor due to its aggressive clinical behaviour and histological features ${ }^{(3,4.5)}$.

\section{Case Report}

A 44 year old male presented with swelling in the right popliteal region since 3 months. Physical examination revealed a round to oval, partially fixed, non tender mass measuring $3 \times 3 \mathrm{~cm}$ in the right popliteal region.

Fine needle aspiration was performed and it yielded scanty material which was moderately cellular and showed dispersed spindle cells of varying size having oval to elongated nuclei and occasional multinucleate giant cells in the background of occasional adipocytes and muscle fibres (Fig. 1 ) which was suspicious of benign spindle cell lesion with differential diagnosis of -1 . Proliferative fascitis , 2 . Proliferative myositis.

Fine needle aspiration cytology in case of proliferative myositis shows loose clusters of uniform, fibroblast like spindle cells and admixed large, ganglion like cells with eccentric nuclei, prominent nucleoli and abundant cytoplasm. The cytologic appearance of proliferative myositis is characteristic, allowing exclusion of malignancy reliably on FNAC. This diagnosis when supported by clinical findings helps to avoid unnecessary radical surgery.

Excision biopsy was done and sent for histopathological examination. On gross, grey pink to grey brown tissue mass measuring $2.5 \times 2 \times 1 \mathrm{~cm}$ seen and $\mathrm{c} / \mathrm{s}$ - grey pink. On microscopy, sections showed a lesion composed of spindle cells in fascicles. Individual cells have vesicular nuclei, prominent nucleoli and moderate amount of eosinophilic cytoplasm ( Fig. 2 ). Myxoid change, extravasation of RBCs and inflammatory cells was seen in the background. Based on these microscopic findings, a final diagnosis of Nodular fascitis was made. 


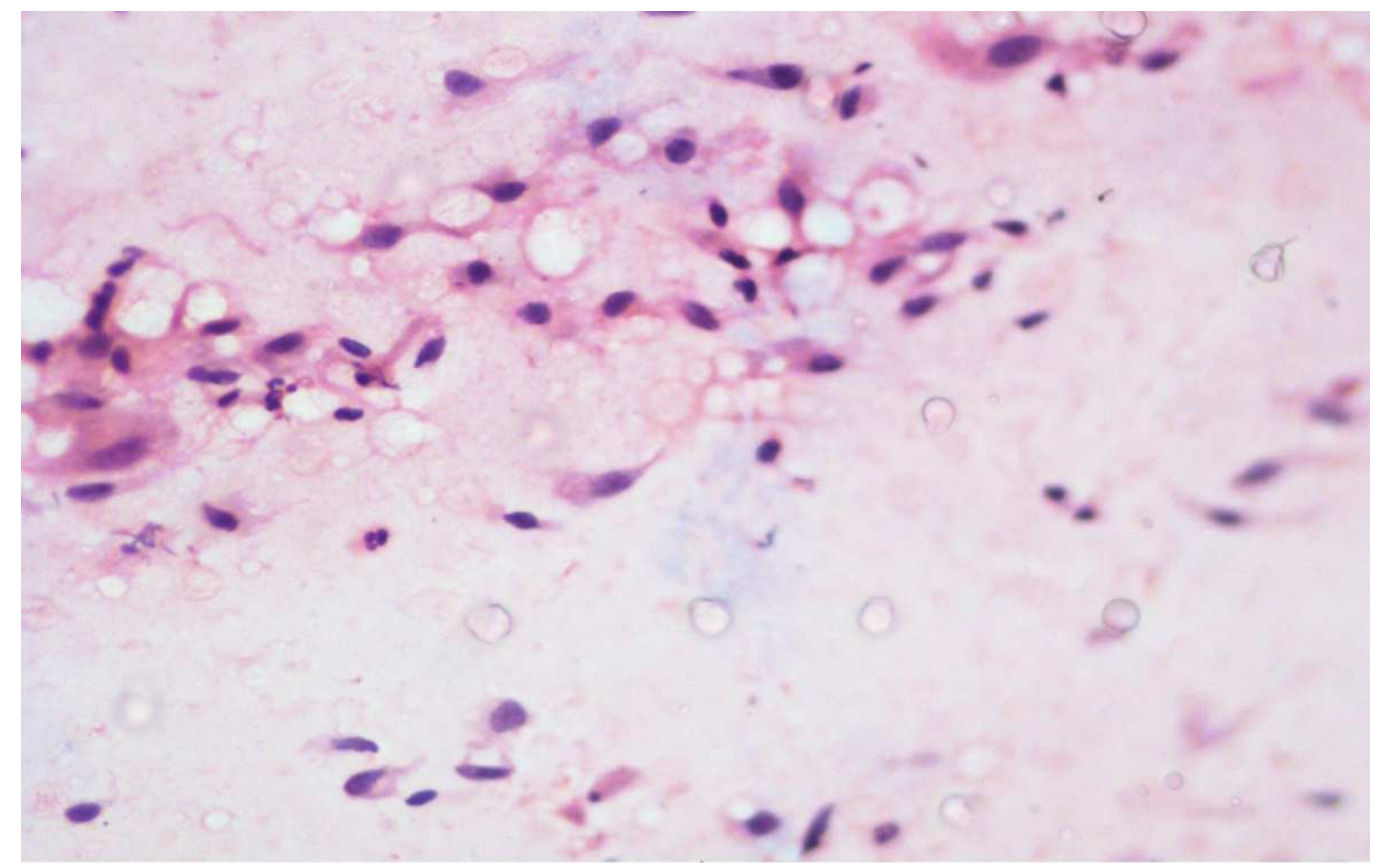

Figure 1. Proliferative fascitis(cytology):Moderately cellular and show dispersed spindle cells of varying size having oval to elongated nuclei in the background of occasional adipocytes and muscle fibres $(H \& E, 40 X)$

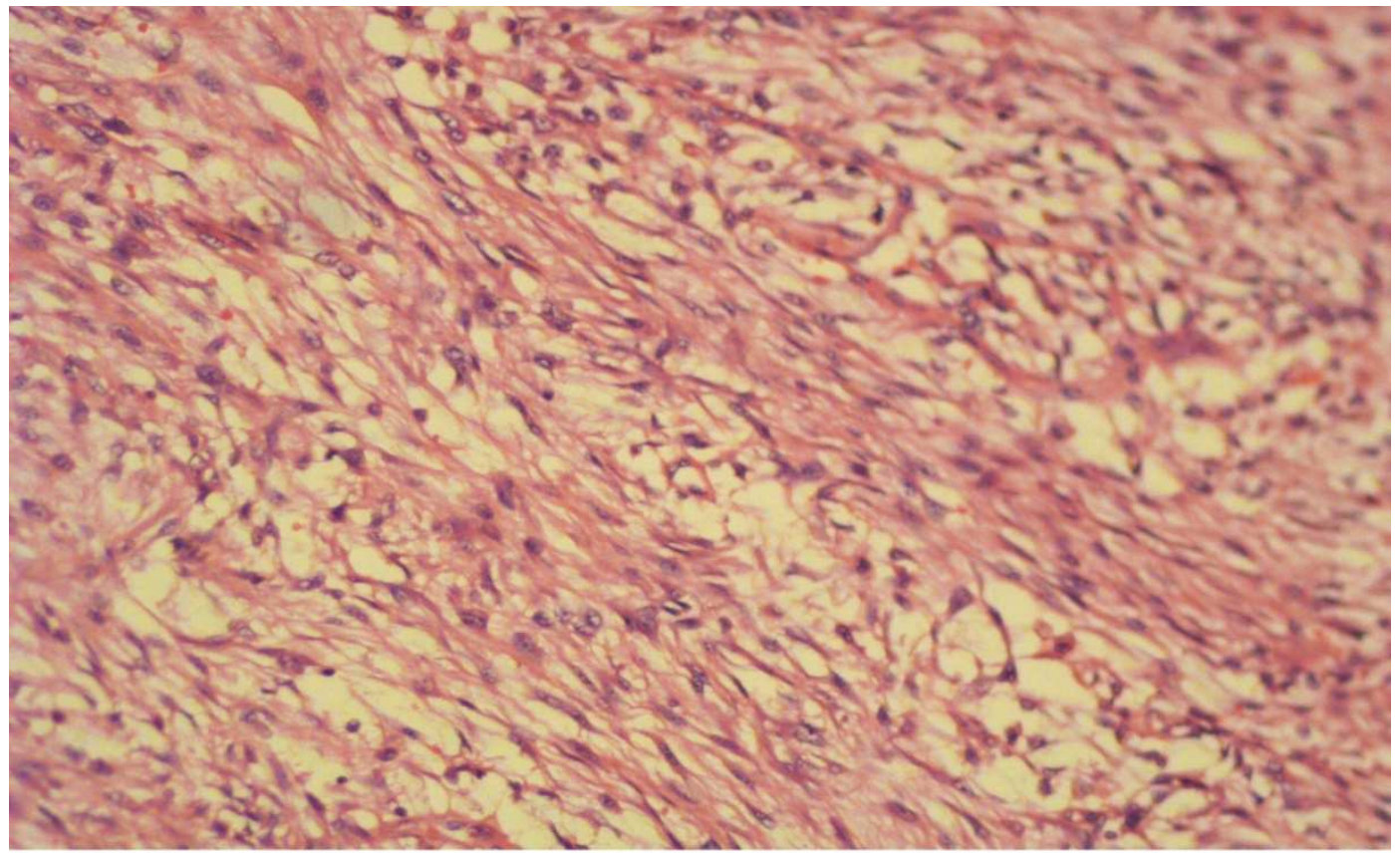

Figure 2. Proliferative fascitis-Sections show a lesion composed of spindle cells in fascicles.Individual cells have vesicular nuclei,prominent nucleoli and moderate amount of eosinophilic cytoplasm(HPPE,40X)

\section{Discussion}

Nodular fascitis is a benign, pseudosarcomatous proliferative lesion of the soft tissue which is frequently misinterpreted as sarcoma, both clinically as well as microscopically ${ }^{(3)}$. It is characterized by rapid growth and requires its differentiation from other less tumorous lesions. It can pose a diagnostic dilemma for pathologists due to its histological similarity with other soft tissue tumors of fibroblastic / myofibroblastic differentiation (2,6). Nodular fascitis can occur anywhere in the body, but most common site is in the upper extremity, especially in the volar aspect of the forearm followed by upper trunk then by head \& neck region. It grows rapidly and has a preoperative duration of not more than $1-2$ months ${ }^{(3,7,8)}$.

Nodular fascitis can be classified into three subtypes Subcutaneous, Intramuscular and Fascial ${ }^{(9)}$ Etiology is unknown but some report trauma to the site of lesion. One theory on its pathogenesis is due to unusual proliferation of 
myofibroblasts triggered by local injury or an inflammatory process ${ }^{(3)}$.

Cytological diagnosis of nodular fascitis is important since it obviates the need for surgical excision. Histopathologically, the lesion is characterised by a cellular spindle cell growth set in a loosely textured mucoid matrix ${ }^{(1,8)}$. The lesion may be highly cellular, but typically it is atleast partly loose appearing and myxoid with a torn feathery or tissue culture like character. Extravasated blood, chronic inflammatory cells and huge multinucleated giant cells are common features of diagnostic significance. Features like absence of atypia, absence of atypical mitotic figures, small size, short history, superficial location helps to rule out malignant tumor (3).

Immunohistochemistry of nodular fascitis demonstrates focal smooth muscle and muscle specific actin and calponin, but not usually desmin, $\mathrm{h}$ - caldesmon or CD34. ${ }^{(9)}$ Local excision is the treatment of choice and recurrence is rare. Spontaneous regression has also been reported. Rapid resolution of the nodule has been reported to occur with intralesional corticosteroid injection ${ }^{(3,10)}$.

\section{Conclusion}

Fine needle aspiration cytology is reliable, minimally invasive and cost effective procedure which helps to differentiate malignant and benign soft tissue tumors. This also helps the clinician to plan the mode of treatment and avoid unnecessary radical surgeries. Further confirmation is done by histopathological examination and immunohistochemistry.

\section{References}

[1] MMA Jayawickrama, HRRG Jayasekara and MVC de silva. Vol. 50, No. 4, Dec 2005

[2] O Hyun Kwon, MD, Kil Ho Cho,MD, jang Ho Suh,MD, Joon Hyuk Choi,MD. J Korean Soc Radiol ;71:254-257, 2014.

[3] Kuladeepa Ananda Vaidya, Medha Shankarling and Sukesh. Indian journal of medical case reports ISSN : 2319-3832 ( online ).Vol. 3, 2014.

[4] Enzinger W. Soft tissue Tumours. $3^{\text {rd }}$ ed. St Louis:Mosby Year book, 1995

[5] Enzinger FM, Dulcey F. Proliferative myositis; Report of 33 cases ;20:2213-23, 1967.

[6] Varshney S, Bhagat S, Bist SS, Mishra S, Shirazi N, Agarwal $\mathrm{V}$ and Kabdwal N. Nodular fasciitis of Neck in childhood. The online journal of Health and Allied Sciences. 11; 132012. Available : http://www.ojhas.org/issue44/2012-4 13.html

[7] Zuber TJ and Finley JL. Nodular fasciitis. Southern Medical Journal $87 ; 842-4,1994$.

[8] Mallina S, Rosalind S, Phillip R, Harvinder S, Gurdeep S and Sabaria MN . Nodular fasciitis: A diagnostic dilemma. Medical journal of Malaysia 62 420-1, 2007.

[9] Mulier S, Stas M, Delabie J, et al. Proliferative myositis in a child: a case report. Skeletal Radiol 1999;28:703-709.

[10] Batsakis JG, elNaggar AK. Pseudosarcomatous proliferative lesions of soft tissues. Ann Otol Rhinol Laryngol 1994;103:578-582. 